Argyro Fassoulaki MD PhD DEAA, Constantine Sarantopoulos MD DEAA, ${ }^{*}$ George Karabinis, Christos Derveniotis MD

\title{
Skin application of isoflurane attenuates the responses to a mechani- cal and an electrical stimulation
}

Purpose: This prospective randomized crossover study was performed to test the potential of an analgesic effect of isoflurane after its local application to the skin.

Methods: We evaluated the local analgesic effect of isoflurane solution in 31 healthy volunteers. The right or left forearm of each subject was exposed to isoflurane and the contralateral forearm to water for $30 \mathrm{~min}$. Then, the response of both forearms to a mechanical stimulus of $650 \mathrm{gr}$ and an electrical stimulus of $2 \mathrm{~Hz}$ was tested. The procedure was repeated the next day with the forearms exposed to anaesthetic or water in an inverse way. The averaged responses to the mechanical and electrical stimuli obtained from both forearms after exposure to isoflurane were expressed on a VAS scale and compared with the averaged responses obtained after exposure to water, using the Wilcoxon signed-ranks matched-pairs test.

Results: The average VAS scores obtained from both forearms after the mechanical stimulus were decreased after isoflurane compared with water $(3.5 \pm 2.1 \mathrm{~cm}$ vs $4.3 \pm 2.2 \mathrm{~cm}, P<0.000 \mathrm{I})$. After the electrical stimulus local application of isoflurane was associated with a decrease in the VAS scores obtained from both the right and left forearms $(3.6 \pm 2.0 \mathrm{~cm})$ when compared with water, $(5.2 \pm 2.1 \mathrm{~cm}, P<0.0001)$.

Conclusion: These data suggest that isoflurane may have an analgesic effect in the peripheral tissues, which may interfere with the MAC determination as well with decreased responses to other nociceptive stimuli.

Objectif : La présente étude randomisée et croisée a été réalisée pour vérifier le potentiel de l'effet analgésique de l'isoflurane après son application locale sur la peau.

Méthode : Nous avons évalué l'effet analgésique local d'une solution d'isoflurane chez 31 volontaires bien portants. L'avant-bras droit ou gauche de chaque sujet a été exposé à l'isoflurane et l'autre avant-bras exposé à l'eau pendant $30 \mathrm{~min}$. La réaction des deux avant-bras à un stimulus mécanique de $650 \mathrm{gr}$ et à un stimulus électrique de $2 \mathrm{~Hz}$ a ensuite été évaluée. La démarche a été reprise le jour suivant en inversant le procédé. Le calcul des réactions moyennes aux stimuli mécanique et électrique, obtenu à partir des deux avant-bras exposés à l'isoflurane, a été exprimé sur l'EVA et comparé au calcul des réactions moyennes obtenu après l'exposition à l'eau, en utilisant le test de rang et d'appariement de Wilcoxon.

Résultats : Le niveau moyen obtenu à l'EVA pour les deux avant-bras, après le stimulus mécanique, a diminué suivant l'administration d'isoflurane, comparé à l'eau $(3,5 \pm 2,1 \mathrm{~cm}$ vs $4,3 \pm 2,2 \mathrm{~cm}, P<0,0001)$. Après le stimulus électrique, l'application locale de l'isoflurane a été associée à un niveau plus bas de douleur à l'EVA, pour les deux avant-bras $(3,6 \pm 2,0 \mathrm{~cm})$, comparé à l'eau $(5,2 \pm 2,1 \mathrm{~cm}, P<0,0001)$.

Conclusion : Ces résultats permettent de présumer que l'isoflurane peut produire un effet analgésique sur les tissus périphériques, effet qui peut interférer avec la détermination de la CAM autant qu'avec la réduction des réactions à d'autres stimuli nocioceptifs.

From the Department of Anaesthesia, St Savas Hospital, 171 Alexandras Ave, 11522 Athens, Greece.

Address correspondence to: A. Fassoulaki, 57-59 Raftopoulou street, 11744 Athens, Greece. Phone: $+301-9024530$ (Home); +301

6430811-19 (Hospital); Fax: +301-6421022 .

* Present address: Department of Anesthesiology, Medical College of Wisconsin, Milwaukee, WI

Accepted for publication September 30, 1998 


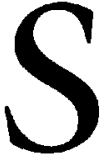

UBANAESTHETIC concentrations of isoflurane have been used in labour ${ }^{1-3}$ to produce analgesia. In humans, isoflurane in subanaesthetic concentrations depresses the nociceptive reflex to single but not to repetitive stimuli, the latter being depressed only by concentrations known to produce surgical anaesthesia. ${ }^{4}$ In animal studies isoflurane suppresses spinal sensitization. ${ }^{5}$ However, evaluation of an analgesic effect of isoflurane is complicated by distingushing between the attenuated responses associated with concentrationdependent sedation and a real analgesic effect.

The aim of the present study was to evaluate the potential antinociceptive effect of isoflurane, minimizing the influence of central depression and/or sedation. Isoflurane was applied locally to the skin and the responses of the skin to a mechanical and an electrical stimulus were assessed.

\section{Methods}

\section{Subjects and Study Design}

The study was approved by the local Ethics Commitee and written informed consent was obtained. Thirty one volunteers, 14 men and 17 women, aged $19-43 \mathrm{yr}$ were recruited for the study. Inclusion criteria were ASA physical status classification I, body weight within $15 \%$ of the ideal body weight, with no history of allergy to previous anaesthetics, tape, cotton, plastic or metal, or of chronic or acute pain, and no consumption of analgesics or other drugs for the last two weeks. For women the potential of pregnancy was excluded based on the history (dates of menstrual cycle or anticontraception). Study subjects were surgery residents and nurses working in the operating room: all of whom were right handed. The stimulation tests and the visual analogue scale (VAS) to evaluate the intensity of the stimulus were explained to all subjects, who had a trial test one or two days before the first experiment to familiarize them with the procedure. The VAS consisted of a $10 \mathrm{~cm}$ line with no pain corresponding to the beginning and worst pain to the end of this line. The subject marked the line according to the pain intensity experienced. The subjects were not aware of the purpose of the study. The study was designed in a controlled, double blind, randomized fashion for the first experiment, and order for cross-over.

\section{Mechanical and Electrical Stimuli}

Subjects were tested for a mechanical and an electrical stimulus.

a) For mechanical stimulation we used, as in previous studies, ${ }^{6,7}$ a pressure palpator, which exerts consis tently 650 gr (pressure FEELER 650 gr Sedatelec; Chemin des Muriers, Irigny, France). The palpator was applied firmly to the volar surface of the lower third of each forearm (five patient finger breadth above the wrist folds) for $30 \mathrm{sec}$. The area stimulated by the pressure probe was approximately the distal cross sectional area of a thick ball-pen. The VAS score for each forearm corresponding to the mechanical stimulus was obtained.

b) For electrical stimulion, a $30 \mathrm{~mA}, 2 \mathrm{~Hz} 0.25 \mathrm{msec}$ square wave electrical impulse, was applied in the same sequence and to the same area but two to three fingers distal to the mechanical stimulus to avoid possible short lasting hyperalgesia caused by the $30 \mathrm{sec}$ pressure stimulation. A peripheral nerve stimulator (MiniStim $\circledast$ Model MS-1) was used with two metal ball electrodes. The delivered current could be varied. The VAS score corresponding to the response to the electrical stimulus was obtained.

\section{Procedure}

Experiments were performed in a quite room with a temperature $20-22^{\circ} \mathrm{C}$. The subject was sitting comfortably with both forearms leaning on a table and the volar surfaces exposed to the investigator. Both the subject and the investigator were wearing surgical masks to prevent them from possible recognition of the forearm with isoflurane. The distal two thirds of each forearm were wrapped with a cotton band. Two $10 \mathrm{ml}$ plastic syringes, each containing $10 \mathrm{ml}$ liquid isoflurane or water were prepared by the investigator and applied almost simultaneously under the cotton band in the space between the cotton and the skin of the volar surface of the arm. Immediately after, both arms were wrapped tightly with aluminum foil from below the elbow fold to the wrist fold. The aluminum foil was covered with a transparent plastic film and the ends of all the wrapping layers were fixed to the proximal (elbow) and distal (wrist) ends with tape. Isoflurane or water was applied to the right or left forearm randomly using sealed envelopes containing an odd or an even number obtained from a computer generated table. For an odd number isoflurane was applied to the right forearm, for an even number to the left forearm, the other forearm serving as control, received water.

Thirty minutes later, the plastic film, the aluminum foil and the cotton were removed simultaneously from both forearms by the same investigator. An independent investigator was involved with the stimulus application and acquisition of the VAS scores. This investigator was also wearing a surgical mask and was 
not aware of the solution applied to each forearm nor of the purpose of the study. He was instructed to apply first the mechanical and then the electrical stimulus. The forearm to be tested first was decided by tossing a coin but the sequence of tests was always the same.

One day later the procedure was repeated. The second experiment was performed in a sequential rather than a randomized manner. The forearm tested for the isoflurane solution in the first experiment served now as the control forearm, tested for water while the forearm tested previously for water was now tested for isoflurane.

\section{Statistical analysis}

The sample size required to ensure a power 0.90 in detecting a clinically relevant difference of $1.5 \mathrm{~cm}$ in the VAS scale was found to be approximately 21 volunteers for an alpha error of 0.05 . An estimated standard deviation 2.1 was used based on initial pilot observations.

Patient characteristics and VAS scores are given as mean $\pm S D$. The averaged VAS scores obtained from both forearms after isoflurane were compared with the averaged VAS scores obtained from both forearms after water. For all comparisons the Wilcoxon signedranks matched-pairs test was used. $P<0.05$ was considered statistically significant.

\section{Results}

Participant characteristics included age $32 \pm 6 \mathrm{yr}$, weight $68 \pm 14 \mathrm{~kg}$ and height $171 \pm 11 \mathrm{~cm}$.

\section{Mechanical stimulus}

Local application of isoflurane resulted in attenuation of the average response of both forearms to the mechanical stimulus by $19 \%$. The mean value of the VAS scores obtained from both forearms with the pressure palpator stimulus after isoflurane was lower than the mean value of VAS scores following water application $(3.5 \pm 2.1 \mathrm{~cm} v s 4.3 \pm 2.2 \mathrm{~cm}, P<0.0001)$ (Table).

TABLE VAS scores (cm) obtained after the mechanical and the electrical stimulus and averaged from both forearms for isoflurane and water applications. Values are mean $\pm S D$.

\begin{tabular}{lll}
\hline & Isoflurane & Water \\
\hline $\begin{array}{l}\text { Mechanical stimulus } \\
\text { mean of both arms }\end{array}$ & $3.5 \pm 2.1^{\star}$ & $4.3 \pm 2.2^{\star}$ \\
$\begin{array}{l}\text { Electrical stimulus } \\
\text { mean of both arms }\end{array}$ & $3.6 \pm 2.0 \dagger$ & $5.2 \pm 2.1 \dagger$ \\
\hline
\end{tabular}

${ }^{\star} P<0.0001, \dagger P<0.0001$

\section{Electrical stimulus}

The mean VAS score from the right and left forearms obtained after electrical stimulation was decreased by $31 \%$ by isoflurane compared with the VAS after water application. The mean VAS scores obtained from the averaged responses of both forearms after a $2 \mathrm{~Hz}$ twitch stimulus were $3.6 \pm 2.0 \mathrm{~cm}$ for isoflurane and $5.2 \pm 2.1 \mathrm{~cm}$ for water $(P<0.0001)$ (Table).

\section{Discussion}

Isoflurane applied directly to the skin for $30 \mathrm{~min}$ decreased the VAS scores to mechanical and electrical stimulus by $19 \%$ and $30 \%$ respectively. Clinical studies in humans have shown that subanaesthetic concentrations of isoflurane produce analgesia in labour. ${ }^{1-3}$ However, the evaluation of possible antinociceptive properties of general anaesthetics in humans is complex as concurrent central depression may interfere with assessing the potential of an analgesic effect.

Petersen-Felix et al. ${ }^{4}$ reported that high concentrations of isoflurane producing surgical anaesthesia, but not subanaesthetic concentrations, depress the nociceptive reflex to repetitive stimuli. Also subanaesthetic concentrations of isoflurane had no effect on the responses to heat, cold or mechanical pressure. ${ }^{8}$ Nonetheless, a depression of the nociceptive reflex to single electrical stimulation was demonstrated in both studies. ${ }^{4,8}$

In contrast to the results of previous investigators, in our study local application of isoflurane to the volar surface of the forearm depressed the response to mechanical stimulation. The different results may be attributed to the different experimental design. In the study of Petersen-Felix et al. ${ }^{8}$ the subjects were allowed to breathe subanaesthetic concentrations of isoflurane for 15 min equilibration at constant end-tidal subanaesthetic concentrations before the series of tests were performed. In our study, the skin was directly exposed to isoflurane for $30 \mathrm{~min}$, probably resulting in an effective anaesthetic partial pressure in the skin and in the primary afferent nerve fibres at this site.

An effective anaesthetic partial pressure in a tissue compartment will be associated with anaesthetic action. ${ }^{9}$ It is hard to predict the isoflurane partial pressure within the skin tissue and nerve endings after local application and compare it with that in the clinical setting, where isoflurane is administered by inhalation. Inhaled isoflurane crosses the skin and percutaneous losses have been demonstrated.$^{10}$ In this case the partial pressure in the periphery is expected to vary and will be determined by the parameters governing the anaesthetic uptake by the different compartments. On the other hand, the anaesthetic uptake by the skin via the epidermis may differ from the 
uptake process via the underlying tissues. In addition, the two minutes needed to complete the testing procedure probably allowed some loss of isoflurane from the skin to the air. The method we developed in the present study allows evaluation of possible analgesic effects of isoflurane with no or minimal involvement of central depression and sedation. We did not control isoflurane traces in expired air for technical reasons but volunteers did not feel sedated. We allowed a $\mathbf{3 0}$ min period of exposure of the skin to isoflurane. As in a previous study the maximal rate of percutaneous loss of three volatile anaesthetics was observed after $\mathbf{3 0}$ min of inhalation. ${ }^{10}$ Nonetheless, to correlate the time constants of skin uptake during general anaesthesia with those during direct exposure of the skin to the anaesthetic is only a speculation.

The potential of an analgesic effect produced by inhalational anaesthetics is consistent with the findings of Rehberg $e t a l .{ }^{11}$ who reported suppression of central nervous system sodium channels by clinical concentrations of volatile anaesthetics. Suppression of sodium currents should lead to an elevation in neuronal firing threshold, ${ }^{12}$ and volatile anaesthetics at clinical concentrations have been shown to elevate the threshold potential of neurons. ${ }^{13}$

If these results apply to the primary afferent fibres, then an effective partial pressure of the volatile anaesthetic at this site may suppress the neuronal excitability and/or conductance and affect the MAC determination. It has been reported that MAC does not change with the duration of anaesthesia. ${ }^{14}$ More recently Petersen-Felix et al. reported a $20 \%$ decrease in MAC during the administration of anaesthesia and surgery. ${ }^{15}$ This could be explained by an effective anaesthetic partial pressure, and therefore a higher firing threshold, at the site where the painful stimulus is applied. The effective partial pressure in the skin is not expected to occur in the early stages of anaesthetic uptake during equilibration of the end-tidal concentration with the central compartment.

We do not know whether the local isoflurane concentrations achieved in the present experimental setting are also reached during clinical anaesthesia. However, all other kinetic parameters remaining constant the skin isoflurane concentration will vary with time, with an hysteresis from the end-tidal anaesthetic concentration. This may have an impact on the peripheral analgesic effect of isoflurane during anaesthesia and therefore on MAC determination. A strong possibility exists that isoflurane is absorbed from the skin into the blood. Since no blood levels and/or breath analysis for isoflurane are available, even in the absence of sedation, a combined peripheral and central effect can not be ruled out.
Skin might be cooled by evaporation of isoflurane and/or water so contributing to VAS changes. However, the possibility of evaporation was limited as the skin area tested was not exposed to air after isoflurane or water application but isoflurane or water were readily absorbed by cotton. In fact 30 min later when the wrappings were removed the skin of the forearms was dry.

In conclusion, our results showed a decreased response to mechanical and electrical stimulataion by local application of isoflurane. In the clinical setting, factors affecting the uptake of anaesthetic by the skin may affect the responses to painful stimuli and thus MAC values. So, for the same alveolar and/or brain concentration of the anaesthetic the same painful stimulus might be associated with different response determined by the skin partial pressure of the anaesthetic.

\section{References}

1 McLeod DD, Ramayya GP, Tunstall ME. Self-administered isoflurane in labour. A comparative study with entonox. Anaesthesia 1985; 40: 424-6.

2 Abboud TK, Gangolly J, Mosaad P, Crowell D. Isoflurane in obstetrics. Anesth Analg 1989; 68: 388-91.

3 Wee MYK, Hasan MA, Thomas TA. Isoflurane in labour. Anaesthesia 1993; 48: 369-72.

4 Petersen-Felix S, Arendt-Nielsen L, Bak P, Fischer M, Bjerring $P, Z$, $b$ inden $A M$. The effects of isoflurane on repeated nociceptive stimuli (central temporal summation). Pain 1995; 64: 277-81.

5 O'Connor TC, Abram SE. Inhibition of nociceptioninduced spinal sensitization by anesthetic agents. Anesthesiology 1995; 82: 259-66.

6 Fassoulaki A, Sarantopoulos C, Zotou M. Nitrous oxide enhances the level of sensory block produced by intrathecal lidocaine. Anesth Analg 1997; 85: 1108-11.

7 Fassoulaki A, Zotou M, Sarantopoulos C. Effect of nimodipine on the regression of spinal analgesia. $\mathrm{Br} J$ Anaesth 1998; 81: 358-60.

8 Petersen-Felix $S$, Arendt-Nielsen $L$, Bak $P$, et al. Analgesic effect in humans of subanaesthetic isoflurane concentrations evaluated by experimentally induced pain. Br J Anaesth 1995; 75: 55-60.

9 Eger EI II, Koblin DD, Harris RA, et al. Hypothesis: inhaled anesthetics produce immobility and amnesia by different mechanisms at different sites. Anesth Analg 1997; 84: 915-8.

10 Fassoulaki $A$, Lockbart SH, Freire, et al. Percutaneous loss of desflurane, isoflurane, and halothane in humans. Anesthesiology 1991; 74: 479-83.

11 Rebberg $B$, Xiao $Y-H$, Duch DS. Central nervous system sodium channels are significantly suppressed at clinical concentrations of volatile anesthetics. Anesthesiology 1996; 84: 1223-33. 
12 Matzner O, Devor $M$. $\mathrm{Na}^{+}$conductance and the threshold for repetitive neuronal firing. Brain Res 1992; 597 : 92-8.

13 Butterworth JF IV, Raymond SA, Roscoe RF. Effects of halothane and enflurane on firing threshold of frog myelinated axons. J Physiol 1989; 411: 413-516.

14 Eger EI II, Saidman LJ, Brandstater B. Minimum alveolar anesthetic concentration: a standard of anesthetic potency. Anesthesiology 1965; 26: 756-63.

15 Petersen-Felix $S$, Zbinden AM, Fischer $M$, Thomson DA. Isoflurane minimum alveolar concentration decreases during anesthesia and surgery. Anesthesiology 1993; 79: 959-65. 